\title{
Is Intense Stress Related to the Onset of Brain Cancer? Shedding Some Light on a Literature Gap
}

\section{Panagiotis Pelekasis*}

University of Athens, Athens, Greece

*Corresponding author: Panagiotis Pelekasis, Postgraduate Course "Science of Stress and Health Promotion", Medical School, University of Athens, Soranou Ephessiou Str. 4, Athens, GR-115-27 Athens, Greece, E-mail: pelekasispanagiotis@gmail.com

Rec. Date: Sep 02, 2015; Acc. Date: Sep 15, 2015; Pub. Date: Sep 25, 2015

Copyright: ( 2015 Pelekasis P. This is an open-access article distributed under the terms of the Creative Commons Attribution License, which permits unrestricted use, distribution, and reproduction in any medium, provided the original author and source are credited.

\section{Editorial}

Intense stress has a harmful effect on the human body and is considered as a causative factor for a plethora of disorders [1], while regarding cancer the belief that its onset may be associated with a stressful experience is found in the British, French, and United States medical literature at least as far back as 1701 [2]. Apart from these premature scientific hypotheses, there is evidence that a high proportion of the general population also believes that "stress causes cancer" [3]. Nevertheless, this might not be true since it is still unknown if there is a link between stress and cancer's occurrence. In fact, both epidemiological and molecular biological studies have established that breast cancer is the only type of cancer whose onset could be attributed to intense stress $[4,5]$.

This well-established relationship had a double impact on cancer research. At first, it indicated that the causes of cancer might be much more complex than already thought. The complexity is multiplied even more considering that stress might also have an indirect relationship apart from the direct one, which is explained by the harmful effect of hormones such as cortisol or other biomarkers. Through an analysis of 12,110 working adults $\mathrm{Ng}$ and Jeffery found that stress was linked to well-known factors that could contribute to a malignancy's onset such as fat diet, less frequent exercise and cigarette smoking [6]. Hence, an established link between stress and even one type of cancer makes us wonder if we are really capable of believing that we have adequate knowledge regarding the pathways leading to a malignancy. Apart from this impact, an accelerated stream of research on a possible relationship between stress and the onset of other types of cancer is expected in the following years.

With regard to brain tumors, the current evidence does not allow drawing any kind of conclusion, indicating though that a possible link could exist. In 2011 Cabaniolis et al published a paper that may probably have a great influence in the following years [7]. Comparing 122 adult brain cancer patients with 122 cancer-free controls revealed that there was a kind of relationship between striking life events in the previous 5 years and the onset of brain cancer (O.R. 1.90). Even though a retrospective study is not an absolutely safe way to establish causeeffect relationships, the evidence reported is too important to be passed by.
Since a single paper is not capable of figuring out the stress-brain cancer relationship, there is an urgent need for future studies. In addition, analysis of already available data included in longitudinal studies could shed some light on this literature gap. In any case, it should not be considered as if revealing such a pathway would only cover our needs to file every single variable related to brain cancer's onset. More importantly, the following step of the research will be to search for correlations between stress and disease relapse. Indeed, regarding breast cancer, stress is not only linked to the onset but also to the relapse of the disease [8]. Thus, if stress is a causative factor for brain cancer, it could also be a factor affecting disease recurrence. From the point of view of the Journal of Brain Tumors \& Neurooncology, it is extremely important not only to explore how brain cancer affects the mental health of patients, but also to clear some of the fog regarding the effect of mental health on the occurrence and relapse of brain tumors.

\section{References}

1. Chrousos GP (2009) Stress and disorders of the stress system. Nat Rev Endocrinol 5: 374-381.

2. LeShan L (1959) Psychological states as factors in the development of malignant disease: a critical review. J Natl Cancer Inst 22: 1-18.

3. Wang C, Miller SM, Egleston BL, Hay JL, Weinberg DS (2010) Beliefs about the causes of breast and colorectal cancer among women in the general population. Cancer Causes Control 21: 99-107.

4. Lin Y, Wang C, Zhong Y, et al. (2013) Striking life events associated with primary breast cancer susceptibility in women: a meta-analysis study. J Exp Clin Cancer Res $32: 53$.

5. Antonova L, Aronson K, Mueller CR (2011) Stress and breast cancer: from epidemiology to molecular biology. Breast Cancer Res 13: 208.

6. Ng DM, Jeffery RW (2003) Relationships between perceived stress and health behaviors in a sample of working adults. Health Psychol 22: 638-642.

7. Cabaniols C, Giorgi R, Chinot O, et al. (2011) Links between private habits, psychological stress and brain cancer: a case-control pilot study in France. J Neurooncol 103: 307-316.

8. Ramirez AJ, Craig TK, Watson JP, Fentiman IS, North WR, Rubens RD. (1989) Stress and relapse of breast cancer. BMJ 298: 291-293. 